\title{
Siyah (Ficus carica) ve Beyaz (Ficus alba) İncirlerden Elde Edilen İncir Sütlerinin Antibakteriyel ve Antifungal etkileri
}

\author{
Gökhan Akarca ${ }^{1 *}$, Oktay Tomar ${ }^{2}$ \\ ${ }^{1}$ Afyon Kocatepe Üniversitesi, Mühendislik Fakültesi, Gıda Mühendisliği Bölümü, Afyonkarahisar, Türkiye (ORCID: 0000-0002-5055-2722) \\ ${ }^{2}$ Afyon Kocatepe Üniversitesi, Mühendislik Fakültesi, Gıda Mühendisliği Bölümü, Afyonkarahisar, Türkiye (ORCID: 0000-0001-5761-7157)
}

(Ilk Geliş Tarihi 28 Kasım 2019 ve Kabul Tarihi 30 Aralık 2019)

(DOI: 10.31590/ejosat.652029)

ATIF/REFERENCE: Akarca, G. \& Tomar, O. (2019). Siyah (Ficus carica) ve Beyaz (Ficus alba) İncirlerden Elde Edilen İncir Sütlerinin Antibakteriyel ve Antifungal etkileri. Avrupa Bilim ve Teknoloji Dergisi, (17), 1069-1074.

$\ddot{O} \mathbf{z}$

Bu çalışmada, siyah (Ficus carica) ve beyaz incir (Ficus alba) türlerinden elde edilen incir sütlerinin, bazı gıda kaynaklı patojen bakteri ve küf türleri üzerindeki antibakteriyel ve antifungal etkilerinin belirlenmesi amaçlanmıştır. Araştırma sonucunda en fazla antibakteriyel etki siyah incirin sütünde $17.95 \mathrm{~mm}$ zon çapı ile Escherichia coli üzerinde olduğu, buna karşın en düşük etkinin ise; beyaz incirin sütünde $9.25 \mathrm{~mm}$ zon çapı ile Staphylococcus aureus' a karşı olduğu belirlenmiştir $(\mathrm{P}<0.05)$. En yüksek antifungal etkiyi ise; yine siyah incirin sütünde $19.25 \mathrm{~mm}$ zon çapı ile Rhizopus nigrificans'a karşı göstermiş̧tir. Bunu sırasıyla 17.20 ve $16.72 \mathrm{~mm}$ zon çapları ile Aspergillus flavus ve Mucor racemosus' un izlediği belirlenmiştir $(\mathrm{P}<0.05)$. En düşük antifungal etki ise; beyaz incir sütünde $8.92 \mathrm{~mm}$ zon çapı ile Mucor rasemosus üzerinde gösterdiği tespit edilmiştir $(\mathrm{P}<0.05)$. Ayrıca çalışma soncunda; siyah incir sütününün beyaz incir sütüne kıyasla daha yüksek antibakteriyel ve antifungal etkisinin olduğu ortaya konulmuştur $(\mathrm{P}<0.05)$.

Anahtar Kelimeler: Ficus carica, Ficus alba, İncir sütü, Antibakteriyel, Antifungal.

\section{Antibacterial and Antifungal Effects of Fig Milk Obtained from Black (Ficus carica) and White (Ficus alba) Figs}

\begin{abstract}
In this study, it is aimed to determine antibacterial and antifungal effects of fig milk obtained from black (Ficus carica) and white fig (Ficus alba) species on some foodborne pathogenic bacteria and mold species. As a result of the research, the highest antibacterial effect was found on Escherichia coli with $17.95 \mathrm{~mm}$ zone diameter in black fig milk, whereas the lowest effect was found against Staphylococcus aureus with $9.25 \mathrm{~mm}$ zone diameter in white fig milk $(\mathrm{P}<0.05)$. The black figs milk against Rhizopus nigrificans with $19.25 \mathrm{~mm}$ zone diameter has again the highest antifungal effect. This is followed by Aspergillus flavus and Mucor racemosus with 17.20 and $16.72 \mathrm{~mm}$ zone diameters, respectively $(\mathrm{P}<0.05)$. The lowest antifungal effect; white fig milk with $8.92 \mathrm{~mm}$ zone diameter on Mucor rasemosus was determined $(\mathrm{P}<0.05)$. In addition, as a result of the study; it was found that black fig milk has higher antibacterial and antifungal effects compared to white fig milk $(\mathrm{P}<0.05)$.
\end{abstract}

Keywords: Ficus carica, Ficus alba, Fig milk, Antibacterial, Antifungal.

\footnotetext{
* Sorumlu Yazar: Afyon Kocatepe Üniversitesi, Mühendislik Fakültesi, Gıda Mühendisliği Bölümü, Afyonkarahisar, Türkiye, ORCID: 0000-00025055-2722, gakarca@aku.edu.tr
} 


\section{Giriş}

İncir (Ficus), Moraceae familyasına ait bir tür olup, Dünyada kültürü yapılan en eski meyvelerden birisidir (Solomon ve ark, 2006). Özellikle 1 lık ve kuru iklimlerde, yaygın olarak yetiştirilen yaygın bir türdür (Slavin, 2006). Koyu mordan, yeşil-sarıya değişen renkte meyve rengine sahip olup, bütün olarak çiğ ya da kurutulmuş olarak tüketilmektedir. Taze olarak tüketildiğinde genellikle kabuk kısmı soyulup atılmakta sadece iç, etli kısmı yenilmektedir (Su ve ark, 2002).

İncir özellikle vitaminler ve mineraller açısından çok iyi bir kaynaktır. $100 \mathrm{~g}$ kuru incir meyvesinin tüketilmesi ile insan vücudunun günlük gereksinimi olan demirin $\% 30$ ’u, kalsiyumun $\% 15,8^{\prime} \mathrm{i}$, potasyumun $\% 14^{\prime}$ ü, B1 vitaminin (tiamin) $\% 14^{\prime} \ddot{\text { ü ve B2 }}$ vitamininin (riboflavin) \%7,1'si karşılanabilmektedir. İncir sodyum bakımından ise fakir olup, kolesterol içermez (Vinson ve ark, 2005; Joseph \& Raj, 2011). İncir en çok aspartik asit ve glutamin olmak üzere, 17 tür amino asidi içermektedir (Lianju ve ark, 2003). İncir ayrica, flavonoidler, polifenol ve arabinoz, $\beta$-amirinler, $\beta$-karotinler, glikozitler, $\beta$-setosteroller ve ksantotoksol gibi bazı biyoaktif bileşikler ile (Gilani ve ark, 2008) proantosiyanidinler gibi fenolik bileşiklerin mükemmel bir kaynağıdır (Slatnar, 2011).

İncir sütü; incir ağacının genç dallarından ve ham meyvesinin koparılmasıyla meyve sapından akan beyaz renkli süt görünümünde viskoz bir sıvıdır. Asidik özellikte olan bu sıvı, özellikle geleneksel tedavide halk arasında böbrek kumu dökmede, diş eti yara ve kanamalarında, nasır ve siğillerin tedavisi ile ciltte oluşan lekeleri giderme gibi, pek çok hastalı̆ı̆ın tedavisinde yaygın olarak kullanılmaktadır (Say ve ark, 2012; Say ve Güzeler, 2016).

Bu çalışmada; siyah (Ficus carica) ve beyaz incir (Ficus alba) türlerinden elde edilen incir sütlerinin bazı gıda kaynaklı patojen bakteri ve küf türleri üzerindeki antibakteriyel ve antifungal etkilerinin belirlenmesi amaçlanmıştır.

\section{Materyal ve Metot}

\subsection{Materyal}

Araştırmada Siyah (Ficus carica) ve beyaz (Ficus alba) olmak üzere iki farklı incir türünden elde edilen incir sütleri kullanılmıştır. İncir sütleri, Temmuz-Ağustos ayları arasında Aydın ili ve ilçelerine bağlı köylerdeki incir bahçelerinden kopartılan ham meyvelerinin sap kısmından akıtılarak elde edilmiştir. Elde edilen sütler analizleri tamamlanıncaya kadar ağzı kapalı cam şişeler içerisinde, karanlık ortamda ve soğuk şartlar altında $\left(4^{\circ} \mathrm{C}\right)$ muhafaza edilmişlerdir.

\subsection{Araştırmada Kullanılan Mikroorganzimalar}

Çalışmada test bakterileri olarak Escherichia coli (ATCC 25922), Listeria monocytogenes (ATCC 51774), Staphylococcus aureus (ATCC 6538), Salmonella pullorum (ATCC 19945) ve Shigella dysenteriae ATCC 13313, test küfleri olarak ise; Aspergillus flavus (ATCC 204304), Penicillium citrinum (ATCC 38065), Botrytis cinerea (ATCC 26943), Mucor racemosus (ATCC 42647) ve Rhizopus nigrificans (ATCC 6227) türleri kullanılmıştır.

\section{3. İncir Sütleri İçeren Disklerin Hazırlanması}

Taze olarak soğuk koşullarda muhafaza edilen iki ayrı incir sütü örneğinden ayrı ayrı 200'er $\mu \mathrm{L}$ steril uçlu otomatik pipet (Research Plus, Eppendorf) yardımı ile, petri kutuları (Steril, 90 x 15, Fıratmed, Türkiye) içerisine alınarak, üzerine boş antibiyotik diskleri (Bio-Disk 316010001) yerleştirilmiştir. Disklerin incir sütlerini emmesi için petri kutuları kapakları kapalı şekilde $60 \mathrm{dk}$ süreyle $4{ }^{\circ} \mathrm{C}$ 'de buzdolabında (Arçelik, 554271, Türkiye) bekletilmiştir. Ardından diskler laminar akışlı kabinde (Cryste, Puricube 1200) kurutulmuştur.

\subsection{Disklerin Antibakteriyel ve Antifungal Aktivite Testlerine Hazırlanması}

Antibakteriyel aktivitenin belirlenmesinde Akarca (2019), antifungal aktivitenin tayininde ise; Alastruey-Izquierdo ve ark, (2015) tarafindan belirtilen yöntemler modifiye edilerek kullanılmıştır.

Antibakteriyel aktivite tayininde spesifik besiyerlerinde (Tablo 1) üretilmiş genç bakteri kültürlerinden (24-48 saatlik), antifungal aktivitenin tayininde ise; Malt Extract Agar (Merck, 1.05398, Almanya) besiyerinde $25{ }^{\circ} \mathrm{C}$ 'de $5-7$ günlük genç kültürlerden, steril bir öze yardımıyla alınarak steril sodyum klorür $(\% 0,9)$ (Merck, 115525, Almanya) içinde süspanse edilmiştir. Her iki analizde de kullanılan suşlarının yoğunluğu McFarland Standartları (0.5) olacak şekilde densinometre (Biosan, 1B, Turkiye) kullanılarak ayarlanmıştır. Yoğunluğu ayarlanan inokulumlar transport swap (Fıratmed, Türkiye) yardımı ile alınarak antibakteriyel aktivite analizi için yeni hazırlanmış $25^{\circ} \mathrm{C}$ 'de, katkısız Muller Hinton Agar (Merck 1,05437, Almanya) (MHA), antifungal aktivite tayini için ise; 25 ${ }^{\circ} \mathrm{C}^{\prime}$ de, \%2'lik glikoz ve $0.5 \mathrm{mg} / \mathrm{L}$ metilen mavisiyle modifiye edilmiş Muller Muller Hinton Agar (Merck, 1,05437, Almanya) yüzeyine homojen bir şekilde inokule edilmiş ve 10 dakika besiyeri tarafindan inokulasyonların emilmesi için beklenmiştir (Bauer ve ark, 1966; Akarca, 2019; Akarca ve ark, 2019). Ardından her birisine $200 \mu \mathrm{L}$ incir sütü emdirilmiş ve kurutulmuş boş antibiyogram disklerden (Bio-Disk 316010001, Türkiye) besiyerlerinin yüzeyine oluşacak zonların bir birisine değmeyeceği uzaklıkta olacak 
şekilde yerleştirilmiş ve petriler antibakteriyel aktivite analizi için EUCAST (2018) de belirtilen koşullarda (Tablo 2), antifungal aktivite tayininde ise; $25^{\circ} \mathrm{C}^{\prime}$ de 5-7 gün süre ile inkubatörlerde (Incucell, MMM, Almanya) inkubasyona bırakılmıştır. Süre bitiminde tüm petri kutularında oluşan zonlar, yeterli günışı̆ı altında digital bir kumpas (Mitutoyo, 500-181-30, Japonya) yardımıyla ölçülmüştür.

Tablo 1. Test Bakterilerinin Üretildiği Besiyerleri ve Koşulları

\begin{tabular}{|c|c|c|c|}
\hline Bakteriler & Kullanılan Besiyeri & İnkubasyon Koşulları & Kullanılan Metot \\
\hline Escherichia coli & $\begin{array}{c}\text { Chromocult TBX Agar (Merck } \\
1.16122)\end{array}$ & $37^{\circ} \mathrm{C}, 24-48 \mathrm{~h}-$ aerobik & $\begin{array}{l}\text { ISO } 16649-1: 2001 \text { (ISO, 2001a) } \\
\text { ISO 16649-2:2001(ISO, 2001b) } \\
\text { ISO 16649-3:2015 (ISO, 2015a) }\end{array}$ \\
\hline Salmonella pullorum & $\begin{array}{l}\text { Brilliant Green Phenol Red Lactose } \\
\text { Sucrose Agar (Merck 1.10747) }\end{array}$ & $37^{\circ} \mathrm{C}, 24-48 \mathrm{~h}-$ aerobik & $\begin{array}{c}\text { ISO } 6579-1: 2017 \\
\text { (Flowers ve ark, 1992, ISO, 2017c) }\end{array}$ \\
\hline Shigella dysenteriae & Endo Agar (Merck 1.04044) & $37^{\circ} \mathrm{C}, 24-48 \mathrm{~h}-$ aerobik & ISO 21567:2004 (ISO, 2015b) \\
\hline
\end{tabular}

Tablo 2. Antibakteriyel Aktivite Tayininde Kullanılan Bakterilere Ait İnkubasyon Koşulları

\begin{tabular}{lcc}
\hline Bakteriler & İkubasyon Koşulları & Kullanılan Method \\
\hline $\begin{array}{l}\text { Escherichia coli } \\
\text { Shigella dysenteriae }\end{array}$ & & \\
$\begin{array}{l}\text { Staphylococcus aureus } \\
\text { Salmonella pullorum }\end{array}$ & $35 \pm 1{ }^{\circ} \mathrm{C}$ aerobik, $16-20 \mathrm{~h}$. & Eucast.org (EUCAST, 2018) \\
Listeria monocytogenes & $35 \pm 1{ }^{\circ} \mathrm{C}, \% 5 \mathrm{CO}_{2}$ ortamda, $16-20 \mathrm{~h}$. & \\
\hline
\end{tabular}

\section{5. İstatistiksel Analizler}

Araştırmada elde edilen sonuçlar, SPSS V 23.0.0 istatistik paket programı kullanılarak hesaplanmıştır. Çalışma çift tekerrürlü ve çift paralel olarak yapılmış, analizler sonucu elde edilen veriler varyans analizi tekniği uygulanarak değerlendirilmiştir. Oluşan farklılıkların düzeyi ise, Duncan testi ile $(\mathrm{P}<0.05)$ belirlenmiştir.

\section{Araştırma Sonuçları ve Tartışma}

İki farklı incirden elde edilen incir sütünün, beş farklı gıda kaynaklı bakteri üzerindeki antibakteriyel etkisi Tablo 3’te gösterilmiştir.

Tablo 3. İki Farklı Incir Sütünün Araştırmada Kullanılan Bakteriler Üzerindeki Antibateriyel Etkisi (mm Zon Çapı)

\begin{tabular}{lcc}
\hline & \multicolumn{2}{c}{ Antibakteriyel Etki (mm zon çapı) } \\
Bakteri Türü & Siyah İncir & Beyaz İncir \\
\hline Staphylococcus aureus & $12.29 \pm 0.65^{\mathrm{Ac}}$ & $9.25 \pm 0.89^{\mathrm{Bb}}$ \\
Salmonella pullorum & $15.60 \pm 1.29^{\mathrm{Aab}}$ & $11.75 \pm 1.11^{\mathrm{Bab}}$ \\
Listeria monocytogenes & $13.89 \pm 1.54^{\mathrm{Ac}}$ & $10.50 \pm 0.58^{\mathrm{Bab}}$ \\
Escherichia coli & $17.95 \pm 0.57^{\mathrm{Aa}}$ & $11.05^{\mathrm{Aa}} \pm 0.83^{\mathrm{Bab}}$ \\
Shigella dysenteriae & $14.67 \pm 0.71^{\mathrm{Aab}}$ & $13.11 \pm 0.94^{\mathrm{Ba}}$ \\
\hline
\end{tabular}

a - c $(\downarrow)$ : Aynı harfleri taşıyan ortalamalar arasında fark istatistiksel olarak önemli değildir ( $p>0.05)$.

A - B $(\rightarrow)$ : Aynı harfleri taşıyan ortalamalar arasında fark istatistiksel olarak önemli değildir ( $p>0.05)$.

En fazla antibakteriyel etkinin, siyah incirden (Ficus carica) elde edilen sütünde $17.95 \mathrm{~mm}$ zon çapı ile Escherichia coli üzerinde olduğu, buna karşın en düşük etkinin ise; beyaz incirden (Ficus alba) elde edilen incir sütünde 9.25 mm zon çapı ile Staphylococcus aureus'a karşı olduğu belirlenmiştir $(\mathrm{P}<0.05)$. 
Siyah incirden elde edilen incir sütünün, beyaz incirden elde edilene kıyasla araştırmada kullanılan gıda kaynaklı beş farklı bakteri üzerinde daha yüksek antibakteriyel etki gösterdiği ortaya konulmuştur (Tablo 4; P<0.05).

Jeong ve ark, (2009) çalışmalarında araştırma sonuçlarımıza paralel şekilde siyah incirin (Ficus carica) metanol ekstraktının özellikle ağız kökenli bakteriler üzerinde yoğun antibakteriyel etki gösterdiği belirtmişlerdir.

Tablo 4. İki Farklı İncirden Elde Edilen Sütlerin Antibakteriyel ve Antifungal Etkilerinin Değerlendirilmesi

\begin{tabular}{lcc}
\hline & Antibakteriyel Etki & \\
Bakteri Türü & Siyah İncir & Beyaz İncir \\
\hline Staphylococcus aureus & ++ & + \\
Salmonella pullorum & ++ & + \\
Listeria monocytogenes & ++ & + \\
Escherichia coli & ++ & + \\
Shigella dysenteriae & ++ & Beyaz İncir \\
\hline & Antifungal Etki & + \\
Küf Türü & Siyah İncir & ++ \\
Aspergillus flavus & ++ & ++ \\
Penicillium citrinum & ++ & - \\
Muctrytis cinerea & ++ & + \\
Rhizopus nigricans & ++ & ++ \\
\hline
\end{tabular}

7-9 mm zon çap1: -, 9-12 mm zon çapı: +,12-18 mm zon çapı: ++, >18 mm zon çap1: +++

Yapılan varyans analiz sonuçlarına göre (Tablo 5) incir çeşidi etkileşiminin $\mathrm{P}<0.0001$, mikroorganizma türü etkileşiminin ise, $\mathrm{P}<0.05$ düzeyinde anlamlı olduğu belirlenmiştir.

Tablo 5. Mikroorganizma Türleri, İncir Çeşidi ve Mikroorganizma Türleri x İncir Çeşidi Etkileşimlerinin Varyans Analiz Sonuçları (P Değerleri)

\begin{tabular}{lccc}
\hline & Mikroorganizma Türü & İncir Çeşidi & Mikroorganizma türü x İncir Çeşidi \\
\hline Antibakteriyel Etki & $0.17 *$ & $<0.0001^{* * *}$ & 0.147 \\
Antifungal Etki & $0.04 *$ & $<0.0001^{* * *}$ & 0.06 \\
\hline
\end{tabular}

*P $<0.05,{ }^{* *} \mathrm{P}<0.01,{ }^{* * *} \mathrm{P}<0.0001$, ns: İstatistiksel Açıdan Önemli Değil.

Beş farklı gıda kaynaklı küf üzerinde iki farklı incirden elde edilen incir sütünün antifungal etkisi Tablo 6'da gösterilmiştir.

Tablo 6. İki Farklı İncir Sütünün Araştırmada Kullanılan Küfler Üzerindeki Antifungal Etkisi (mm Zon Çapı)

\begin{tabular}{lcc}
\hline & \multicolumn{2}{c}{ Antifungal Etki (mm zon çapı) } \\
Küf Türü & Siyah İncir & $10.35 \pm 0.68^{\mathrm{Bb}}$ \\
\hline Aspergillus flavus & $17.20 \pm 1.07^{\mathrm{Aab}}$ & $12.91 \pm 0.34^{\mathrm{Ba}}$ \\
Penicillium citrinum & $15.95 \pm 0.47^{\mathrm{Aab}}$ & $13.29 \pm 0.84^{\mathrm{Aa}}$ \\
Botrytis cinerea & $13.87 \pm 1.25^{\mathrm{Ab}}$ & $8.92 \pm 0.3^{\mathrm{Bb}}$ \\
Mucor racemosus & $16.72 \pm 0.53^{\mathrm{Aab}}$ & $14.25 \pm 0.79^{\mathrm{Ba}}$ \\
Rhizopus nigricans & $19.25 \pm 0.97^{\mathrm{Aa}}$ & \\
\hline
\end{tabular}

$\mathrm{a}-\mathrm{c}(\downarrow)$ : Aynı harfleri taşıyan ortalamalar arasında fark istatistiksel olarak önemli değildir $(\mathrm{p}>0.05)$.

A - B $(\rightarrow)$ : Aynı harfleri taşıyan ortalamalar arasında fark istatistiksel olarak önemli değildir $(\mathrm{p}>0.05)$.

Araştırma sonucunda; en yüksek antifungal etkiyi siyah incir (Ficus carica)'den elde edilen incir sütünün, 19.25 mm zon çapı ile Rhizopus nigrificans üzerinde gösterdiği, bunu sırasıly 17.20 ve $16.72 \mathrm{~mm}$ zon çapları ile Aspergillus flavus ve Mucor racemosus'un ve izlediği belirlenmiştir $(\mathrm{P}<0.05)$. Araştırma sonucunda en düşük antifungal etkiyi ise; beyaz incirden (Ficus alba) elde edilen incir sütünün $8.92 \mathrm{~mm}$ zon çapı ile Mucor rasemosus üzerinde gösterdiği tespit edilmiştir $(\mathrm{P}<0.05)$. Ayrıca, siyah incirden elde edilen incir sütünün, beyaz incirden elde edilene kıyasla beş farklı küf türü üzerinde daha yüksek antifungal etki gösterdiği belirlenmiştir (Tablo 4; $\mathrm{P}<0.05$ ). Yapılan varyans analiz sonuçlarına göre (Tablo 5) incir çeşidi etkileşiminin $\mathrm{P}<0.0001$, Mikroorganizma türü etkileşiminin ise $\mathrm{P}<0.05$ düzeyinde anlamlı olduğu belirlenmiştir. 
Aref ve ark, (2010) araştırma sonuçlarımıza benzer şekilde Ficus carica (Siyah incir) etanol ekstraktının Candida albicans üzerinde yüksek derecede etkili antifungal özelliğinin olduğunu bildirmişlerdir.

\section{Sonuç}

İncir sütünün patojen bakteriler ve küfler üzerindeki etkileri araştırılan bu çalışmada yüksek antmikrobiyal etkilere sahip olduğu ortaya konulmuştur. Özellikle siyah incirden (Ficus carica) elde edilen sütün, beyaz incirden (Ficus alba) elde edilene kıyasla çok daha güçlü antibakteriyel ve antifungal özellik gösterdiği tespit edilmiştir.

Bakterilerin günümüzde kullanılan antibiyotiklere karşı gösterdiği direnç her geçen gün daha da artmakta, alternatif tıp olarak adlandırılan bitkiler kullanılarak uygulanan tedavilere verilen önem ise artı̧ göstermektedir. Son yıllarda birçok baharat ve bitkinin farklı kısımlarından elde edilen preparatların antimikrobiyal özelliklerinin araştırılması üzerinde yapılan çalışmalarda olumlu sonuçlar alınmıştır.

Araştırma ile elde edilen veriler değerlendirildiğinde, incir sütünün bu anlamda iyi bir kaynak olacağı açıktır. Doğal, bol bulunan, ucuz ve her kesim tarafından tanınan bir ürün olması, inciri alternatiflerine kıyasla avantajlı kılmaktadır.

\section{Kaynakça}

Akarca, G. (2019). Composition and antibacterial effect on food borne pathogens of Hibiscus surrattensis L. calyces essential oil. Industrial Crops \& Products, 137, 285-289. https://doi.org/10.1016/j.indcrop.2019.05.043

Akarca, G., Tomar, O. \& İstek, Ö. (2019). Determination of apricot tree resin extracted in different solvents for antimicrobial effect. 2nd International Health Sciences and Life Congress (IHSLC 2019), P: 1194-1203, $24-27$ Nisan 2019, Burdur/Turkey.

Alastruey-Izquierdo, A., Melhem, M. S., Bonfietti, L. X. \& Rodriguez-Tudela, J. L. (2015). Susceptibility test for fungi: Clinical and laboratorial correlations in medical mycology. Rev Inst Med Trop Sao Paulo, 57(19), 57-64. https://doi.org/10.1590/s003646652015000700011 .

Aref, H. L., Salah, K. B. H., Chaumont, J. P., Fekih, A., Aouni, M. \& Said, K. (2010). In vitro antimicrobial activity of four Ficus carica latex fractions against resistant human pathogens (antimicrobial activity of Ficus carica latex). Pakistan Journal of Pharmaceutical Sciences, 23(1), 53-58.

Bauer, A. W., Kirby, W. M. M., Sherris, J. C. \& Turck, M. (1966). Antibiotic susceptibility testing by a standardized single disk method. Am J Clin Pathol, 36, 493-496.

EUCAST, (2018). EUCAST, European Commitee on Antimicrobial Susceptibilty Testing, http://www.eucast.org/fileadmin/ src/media/PDFs/EUCAST_files/Breakpoint_tables/v_8.0_Breakpoint_Tables.pdf

Flowers, R. S., D'aust, J. Y., Andrews, W. H. \& Bailey J. S. (1992). Salmonella. Vanderzant, C., Spilttstoesser, D. F. (Ed.), In Compendium of the Methods for the Microbiological Examinations of Foods (pp. 371-422), USA, American Public Health Association.

Gilani, A. H., Mehmood, M. H., Janbaz, K. H., Khan, A. U. \& Saced, S. A. (2008). Ethanopharmacological studies on antispasmodic and antiplatelet activities of Ficus carica. J Ethanopharmacol, 119, 1-5.

ISO. (1999). International Standard Organization, 6888-1 Horizontal Method for the Enumeration of Coagulase - positive Staphylococci Technique using Baird Parker Agar Medium. Geneva, Switzerland.

ISO. (2001a) International Standard Organization, 16649-1:2001 Microbiology of food and animal feeding stuffs - Horizontal method for the enumeration of beta-glucuronidase-positive Escherichia coli - Part 1: Colony-count technique at 44 degrees $\mathrm{C}$ using membranes and 5-bromo-4-chloro-3-indolyl beta-D-glucuronide. Geneva, Switzerland.

ISO. (2001b) International Standard Organization, 16649-2:2001 Microbiology of food and animal feeding stuffs - Horizontal method for the enumeration technique at 44 degrees $\mathrm{C}$ using 5-bromo-4-chloro-3-indolyl beta-D-glucuronide. Geneva, Switzerland.

ISO. (2015a). International Standard Organization, 16649-3:2015 Microbiology of the food chain- Horizontal method for the enumeration of beta-glucuronidase-positive Escherichia coli - Part 3: Detection and most probable number technique using 5bromo-4-chloro-3-indolyl-ß-D-glucuronide. Geneva, Switzerland.

ISO. (2015b). International Standard Organization, 21567:2004 Microbiology of food and animal feeding stuffs - Horizontal method for the detection of Shigella spp. Geneva, Switzerland.

ISO. (2017a). International Standard Organization, 11290-1:2017 Microbiology of the food chain, Horizontal method for the detection and enumeration of Listeria monocytogenes and of Listeria spp. - Part 1: Detection method. Geneva, Switzerland.

ISO. (2017b). International Standard Organization. 11290-2:2017 Microbiology of the food chain, Horizontal method for the detection and enumeration of Listeria monocytogenes and of Listeria spp. - Part 2: Enumeration method. Geneva, Switzerland. 


\section{Avrupa Bilim ve Teknoloji Dergisi}

ISO. (2017c). International Standard Organization, 6579-1:2017 Horizontal method for the detection, enumeration and serotyping of Salmonella. Geneva, Switzerland.

Jeong, M. R., Kim, H. Y. \& Cha, J. D. (2009). Antimicrobial activity of methanol extract from Ficus carica leaves against oral bacteria. Journal of Bacteriology and Virology, 39(2), 97-102. https://doi.org/10.4167/jbv.2009.39.2.97

Joseph, B. \& Raj, S. J. (2011). Pharmacognostic And Phytochemical Properties of Ficus Carica Linn - An Overview. Int J Pharm Tech Res, 3, 8-12.

Lianju, W., Weibin, J., Kai, M., Zhifeng, L., Yelin, W. (2003). Theproduction and research of fig (Ficus carica L.) in China. Acta Hortic, 605, 191-196.

Say, D. \& Güzeler, N. (2016). Süt pıhtılaştırılmasında kullanılan bazı bitkiler. Nevsehir Journal of Science and Technology, TARGID özel Sayı, 253-261.

Say, D., Soltani, M. \& Güzeler, N. (2012). Bazı bitkisel pıhtılaştııııların sütü pıhtılaştırma kuvvetleri. III. Geleneksel Gıdalar Sempozyumu, 10-12 Mayıs, Konya, Türkiye. 701-703.

Slatnar, A., Klancar, U., Stampar, F. \& Veberic, R. (2011). Effect of drying of figs (Ficus carica L.) on the contents of sugars, organic acids and phenolic compounds. Journal of Agricultural and Food Chemistry, 59(21), 11696-11702.

Slavin, J. L. (2006). Figs: Past, Present and Future. Nutrition Today, 41, 180-184.

Solomon, A., Golubowicz, S., Yablowicz, Z., Grossman, S., Bergman, M., Gottlieb, H. E., Altman, A., Kerem, A. \& Flaisman, M. (2006). Antioxidant Activities and Anthocyanin Content of Fresh Fruitsof Common Fig (Ficus carica L.). J Agric Food Chem, 54, 7717-7723.

Su, Q., Rowley, K. G., Itsiopoulos, C. \& O'Dea, K. (2002). Identificationand quantitation of major carotenoids in selected componentsof the Mediterranean diet: green leafy vegetables, figs and oliveoil. Eur J Clin Nutr, 56, 1149-1154.

Vinson, J. A., Zubik, L., Bose, P., Samman, N. \& Proch, J. (2005). Dried fruits: Excellent in Vitro and in ViVo Antioxidants. J Am Coll Nutr, 24, 44-50. 